\title{
Temporality and biography in tourism: a qualitative longitudinal approach
}

\author{
Émilie Crossley* \\ Otago Polytechnic, Dunedin, New Zealand
}

Temporality is increasingly being recognised as an important dimension of tourist experience. Qualitative longitudinal research $(Q L R)$ is a methodology for investigating temporality and change that is rarely used in tourism studies. The approach moves away from reliance on data collected at one point in time and retrospective narratives. Instead, data are generated at multiple points in time, thus capturing experience in the present moment. I situate QLR alongside lifecourse and biographical research in order to show how it can extend existing qualitative enquiry into tourists' subjective temporal experiences and biographical narratives. 'Intensive' and 'extensive' QLR designs are delineated and connected to potential applications in qualitative tourism research. Additionally, conceptual clarification is provided regarding use of the terms 'longitudinal' and 'temporal', which have frequently been a source of confusion. I conclude that QLR has significant potential to advance our understanding of tourist experience, motivation and transformation.

Keywords: methodology, longitudinal, time, temporality, biography, narrative, lifecourse

\section{INTRODUCTION}

Qualitative research is developing an increasingly nuanced appreciation of how time and subjective temporal experience constitute tourism. Time has been theorised as a mediator of tourism discourse, imagination and praxis (Cohen 1986; Edensor 2012; Norum/Mostafanezhad 2016), used to sequence tourists' activities in the form of 'time-budgets' (Fennell 1996; Hall 2005; Krakover 2002; Pearce 1988) and provided a central conceptual framework in the nascent study of slow tourism (Dickinson/ Lumsdon 2010; Dickinson/Peeters 2014; Dickinson et al. 2011; Fullagar et al. 2012; Lumsdon/McGrath 2010; Varley/Semple 2015). Qualitative research on the subjective experience of time has revealed multiple, intersecting temporalities and the effects of rhythm, tempo and pace (Bærenholdt et al. 2004; Dickinson et al. 2013; Elsrud 1998; Germann Molz 2009; 2010; Grabowski et al. 2016; Gram et al. 2019; Ryan 2002; Small 2016; Stein 2012), while biographical and life history research have presented tourists' narratives of the passage of time (Desforges 2000; Huber et al. 2017; Ladkin 1999; Sedgley 2007; Sedgley et al. 2011; Small 1999; Trapp-Fallon 2003; 2007).

This rich field of qualitative enquiry has provided much-needed insight into the temporalities of tourism. The purpose of this paper is to introduce qualitative longitudinal research (QLR) as a complementary methodology, which further elucidates tourists' subjective temporal experience and provides a powerful mechanism for investigating personal transformation through tourism. While it is clear that our theoretical grasp of time in tourism has advanced significantly, I argue that we have

* Email: emilie.crossley@op.ac.nz. 
not seen the necessary concomitant methodological development. Qualitative tourism research still relies heavily on data collected at one point in time and the retrospective framing of experience, which can be problematic when it comes to making analytic claims about change and transformation. The resulting snapshots of social life that we produce through research can elude the dynamic, contradictory nature of temporal subjectivity (Holland/Thomson 2009; Neale/Flowerdew 2003). This approach also risks producing a myopic focus on tourism phenomena, despite the valuable context that tourists' everyday lives can provide for interpreting their actions as tourists (Hall 2005; Lean 2016a; McCabe 2002; Small 1999; White/White 2007).

QLR is an underutilised methodology for exploring change, process and temporality in tourism, which has been too readily dismissed by tourism researchers in the past (see for example Ladkin 2004). The approach seeks to explain how change is experienced across the lifecourse and how individual biographies connect to wider processes of historical change (Holland et al. 2006; McLeod/Thomson 2009; Neale/ Flowerdew 2003; Shirani/Henwood 2011a; 2011b). It aims to capture a 'movie' of social life rather than just a static 'snapshot' by walking alongside individuals as they experience key moments and life transitions (Neale/Flowerdew 2003). Section 2 reviews theorisations that have shaped social scientific understanding of time and temporality, providing conceptual grounding for my subsequent discussion. Section 3 draws on leading-edge research to provide a contemporary portrayal of QLR, including research design, data analysis techniques, ethics and limitations. I challenge the assumption that QLR is too difficult and costly to be undertaken in tourism studies, pointing out how new technologies have enabled qualitative research to be conducted longitudinally in novel ways. Section 4 then reviews research on tourist temporality and biography, juxtaposing QLR with two competing methodologies: lifecourse and biographical research. I show how a longitudinal approach can extend existing qualitative research by providing insight into the emergence and reflexive construction of narratives. I conclude in Section 5 by arguing that QLR has great potential to advance our understanding of tourist experience, motivation and transformation.

\section{TIME, TEMPORALITY AND NARRATIVE}

The 'temporal turn' that is posited as having occurred in the social sciences indicates an epistemological shift that has sensitised researchers to time and temporal experience (cf. Adam 1995; May/Thrift 2003). Thomson/McLeod (2015) suggest that the temporal turn has engendered a critical evaluation of social phenomena in 'greater time perspective', which has generated increased methodological interest in secondary analysis, archival work, inter-generational approaches and QLR. As Henwood/ Shirani (2012: 209, emphasis original) argue, '[t]ime is useful to social researchers as a vehicle of study, because it provides a means of designing studies around key moments, transitions, trajectories ... . It can also be treated as a topic of study, for which the substantive research focus is on how people think about and relate to time'. In this section, I present some of the most prominent themes in sociological and social psychological theorisations of time, subjective temporal experience and narrative. This discussion draws attention to the plurality of time and temporality as social scientific concepts and thus provides important theoretical grounding for my subsequent discussion of QLR.

Sociological research on time has revealed the diversity of temporal subjectivity and experience available to humans, and the ways in which notions of time are 
socially constructed and ideologically invested (Abbott 2001; Adam 1990; 1995; Hassard 1990; Zeruvabel 1981; 1982). For example, Zeruvabel (1981; 1982) and, later, Adam (1990; 1995) challenged naturalised ideas about time by revealing the hegemony of calendars, timetables, schedules and clocks over our lives, which they refer to as 'clock time'. They argue that dominant conceptions of time have displaced other cultural, embodied and subjective temporalities. These marginalised temporalities might include natural bodily rhythms, such as circadian rhythms, which powerfully regulate our embodied temporal experience. We are often not aware of these embodied temporalities until they become desynchronised from the prevailing social experience of time, such as when jet lag causes a long-haul traveller to wake suddenly while others in their new time zone are asleep. Equally, Jones/Brown (2005) note the cultural relativity of time by distinguishing between 'temponomic' societies, which are temporally structured by clock time and 'temponostic' societies, which are not regimented by the clock, prioritise social engagement and do not perceive time as having intrinsic value.

Some theorists have proposed the concept of 'microtemporal' processes in order to 'bring into view the times and textures of people's everyday lives', employing concepts such as pace, tempo and rhythm (Henwood/Finn 2010: 35; Henwood/Shirani 2012; Hollway 2010). The idea of time having 'texture' can be traced back to Flaherty's $(2003 ; 2011)$ qualitative social psychological research on temporal experience. Flaherty (2011: 132) claims that much of 'our temporal experience is designed and realized through agentic practices that operate at both the intrapersonal and interpersonal levels'. Elements of temporal experience over which we can exert control include duration, frequency, sequence, timing and allocation. Flaherty refers to this subjective customisation of temporal experience as 'time work' or 'doing time'. While sociological research on time outlines the broad temporal norms and structures that regulate contemporary society, social psychological research reinjects agency by showing how individual resistance to these norms is possible. For example, despite the hegemony of clock time, we may attempt to influence perceived duration in order 'to make an interval seem longer or shorter than its objective length as measured by the clock or calendar' (Flaherty 2003: 21). So while time is socially regulated, there are creative strategies enacted at the individual level that can enhance our subjective temporal experience while conforming to the imposition of hegemonic constructions of time. For example, a bored student may appear to conform to clock time by waiting until the bell sounds before leaving class but by doodling or daydreaming their subjective temporal experience may be one of decreased duration.

Time can be theorised as existing within layered, intersecting dimensions such as biographical, generational and historical time (Henwood/Finn 2010; Henwood/ Shirani 2012; Neale/Flowerdew 2003). Neale et al. (2012: 5) explain that these are the 'micro, meso and macro dimensions of enquiry through which it becomes possible to understand the dynamic relationship between individual and collective lives, and broader patterns of social change'. Framed in this way, we can begin to see the potential explanatory power of longitudinal research in relation to a variety of contested theoretical dualities at the heart of social science enquiry, such as individual/society, agency/structure or psychological/sociological. Neale/Flowerdew (2003) add a fourth dimension denoting cyclical time, such as anniversaries or seasons, which provide social constructs through which people chart their journey through life. Time can also be theorised in relation to the stages of the lifecourse, such as childhood, adulthood and old age, or life transitions, such as becoming a parent, embarking on a new career or travelling for the first time (Henwood/Finn 2010; 
Holstein/Gubrium 2007; Neale 2015). As researchers, we are therefore challenged to develop a sufficiently complex appreciation of 'how lives unfold collectively (interactively, relationally), and how individual and collective lives shape and, in turn, are shaped by wider historical, structural, spatial and geo-political processes' (Neale 2015: 26).

Personal narratives provide a way of accessing temporal experience. Narratives can be biographical, in that they tell a 'life story', or may be used to express temporal experience in other ways. M.L. Crossley (2000) argues that temporal experience is constitutive of human consciousness and that, as a consequence, we impose a 'narrative structure' on the flow of experience. Drawing on Husserl, M.L. Crossley (2000: 534) explains that '[o]ur experience automatically assumes temporally extended forms in which future, present and past mutually determine one another as parts of a whole', which in turn informs the narrative constructions that we use to interpret and represent our lives. However despite this synergy, narrative is not synonymous with temporal experience. In particular, biographical narratives can retrospectively articulate, rationalise and distort life as actually lived (Wood 2001). Neale/Flowerdew (2003: 193) emphasise the fact that biographical narratives 'build up a picture of the past from the perspective of the present, and the present is understood through the lens of past experiences'. Similarly, Tamboukou (2008) draws attention to the rhetorical, contradictory, non-linear nature of narratives and encourages us to consider them as relational, open-ended stories rather than as accurate representations of the past. Having surveyed the theoretical landscape of time, temporality and narrative, I now turn to QLR as a means of operationalising time as both a vehicle and topic of study, which has great promise for tourism studies.

\section{QUALITATIVE LONGITUDINAL RESEARCH}

Qualitative longitudinal research (QLR) is a term that encapsulates methodologies seeking to comprehend processes and experiences of change that occur through time (Saldaña 2003). Neale/Flowerdew (2003) use the metaphor of moving and still images to explain the difference between longitudinal research, which captures a 'movie' of social life, and non-longitudinal research, which captures a static 'snapshot'. QLR privileges experience in the present moment as opposed to relying on retrospective narratives, which confers the approach with a number of advantages (McLeod/ Thomson 2009). It becomes possible to follow cohorts living through policy changes (Corden/Millar 2007) or major life changes (Shirani/Henwood 2011a; 2011b), capturing the lived experience of transitions in progress. Research methods that rely on retrospection alone can elicit well-rehearsed, coherent and rhetorically persuasive narratives. Qualitative longitudinal methods, on the other hand, may capture emergent narratives in all of their messy complexity. Listening to people's stories at different points in time also allows us to explore how memories of the past and imaginings of the future change and are reinterpreted over time (Neale/Flowerdew 2003; Shirani/ Henwood 2011b). QLR thus provides 'a rich source of understanding of the complexities of the storied life' (Thomson 2007: 572).

The version of QLR that I put forward in this paper has its disciplinary origins primarily in sociology and social psychology. It aims to advance knowledge about biography, subjectivity and experience by tracing individual lives through time (McLeod/Thomson 2009; Neale/Flowerdew 2003; Shirani/Henwood 2011a; 2011b). Much of this recent scholarship has been generated through the Timescapes initiative, 
which was a major study funded by the United Kingdom Economic and Social Research Council (ESRC) that ran from 2007 to 2012 and investigated personal and family relationships (Neale et al. 2012). The Timescapes approach focuses on linkages between individual biographies, inter-subjective dynamics and wider processes of historical change (Henwood/Finn 2010; Neale/Flowerdew 2003). While in this section I draw inspiration from the conceptual and methodological work of the Timescapes network, it should be noted that QLR is characterised by plurality and contestation. Other branches of QLR can be found in social anthropology, education and community studies, which may centre more on how communities or cultures develop over time and show a preference for ethnographic methods (Holland et al. 2006).

\subsection{Research design}

QLR design can be situated in relation to two theoretical planes of time that have been articulated by Neale (2018). The first is 'prospective-retrospective', referring to how people look forwards (prospectively) and backwards (retrospectively) through time, thus providing a fundamental orientation towards time as a linear construct. Research that uses a prospective design follows participants forwards through time, attempting to capture their experience in the present moment through repeated waves of data collection. Research that uses a retrospective design, such as biographical narrative research or memory-work, uses retrospection to interpret the past from the perspective of the present. As well as being useful for conceptualising research design, the 'prospective-retrospective' plane of time can also be employed to characterise the construction of biographical narratives. For example, prospective longitudinal research will inevitably produce retrospective narratives as participants remember and discuss their past. Equally, prospective narratives may be produced through retrospective research as participants imagine the future. Neale's second plane of time is 'intensive-extensive', which refers to research 'tempos' and 'time frames'. Intensive longitudinal research has a short time-frame but involves frequent data collection waves, which results in an increased research tempo. Extensive longitudinal research elapses over a longer time-frame with less frequent waves of data collection, resulting in a slower tempo.

QLR is characterised by its use of prospective longitudinal research design (Neale et al. 2012). Interviews are frequently used to generate data as they are conducive to eliciting narratives of temporal experience (Hermanowicz 2013). However, such narratives can also arise from focus groups or diaries, and many QLR projects make use of complementary ethnographic and visual techniques such as participant observation, graphic elicitation, digital forums or documentary analysis (Bagnoli 2009; Holland et al. 2006; Neale et al. 2012). Where interviews are used as the principal method, these additional techniques can provide valuable multimodal data, as well as helping to keep participants engaged in the research process in between the main waves of data collection. While many of the scholars I feature in this discussion focus on interviews, it should be noted that the methodological and ethical observations that I offer are more broadly applicable in QLR. In particular, there is significant untapped potential regarding the intersection between predominantly interview-based and ethnographic longitudinal research. While interviews allow us to explore the psychology of temporal experience, ethnographic methods may shed light on extra-discursive features of subjectivity 
and inter-subjective dynamics that feed into the co-construction of biographical narratives.

The parameters within which research is considered to be 'longitudinal' are contested. Some researchers suggest the need for data collection to span years or to comprise a minimum number of data collection waves; others argue that engaging qualitatively with temporal experience is more important than strict adherence to particular research time-frames (Hermanowicz 2013; Neale et al. 2012; Thomson/ Holland 2003). Indeed, one perspective is that QLR is best understood as a research 'orientation' that sensitises us to temporality (Shirani/Henwood 2011b; Thomson/ McLeod 2015). Elliot et al. (2008) suggest that a conceptual distinction should be maintained between longitudinal data, which provide information about research cases across multiple points in time, and longitudinal research, which involves generating data across multiples points in time. The distinction between the two is subtle yet important and allows us to differentiate between qualitative research that produces longitudinal data, such as biographical narrative methods, and true longitudinal research that generates data through time, bearing in mind that both approaches may have an analytic focus on temporal experience.

\subsection{Data analysis}

The volume and multi-faceted nature of qualitative longitudinal data presents unique challenges when it comes to data analysis. Derrington (2019) emphasises the importance of managing large data sets effectively and ensuring that coding is carried out in a timely fashion. Data generated through QLR can be analysed using two techniques: synchronic (cross-sectional) analysis or diachronic (longitudinal) analysis (Thomson 2007; Thomson/Holland 2003). The synchronic technique analyses data from multiple cases at a single temporal point, creating cross-sectional 'slices' that can be analysed for changes through time. Diachronic analysis presents a holistic examination of an individual's biographical narratives through time (Yates 2003). The former is useful for identifying shared discourses or experiences while the latter reveals how these shared resources are contextually enacted over time through the construction of personal narratives. It is also possible to combine diachronic and synchronic analysis in order to provide a more complex reading of a data set. These diverse possibilities mean that the analytic workload in QLR can be three times that of a conventional qualitative study, affording as it does the possibility of diachronic and synchronic analysis, plus an additional analytic layer that looks across both dimensions (Holland et al. 2006). Analytic closure can be difficult to achieve due to the ongoing generation of new data, revealing the provisional nature of researchers' interpretations (Henderson et al. 2012; Holland/Thomson 2009; Thomson/Holland 2003).

Beyond the broad distinction between diachronic and synchronic analysis, the way in which qualitative longitudinal data are analysed will depend on the researcher's theoretical orientation. For example, critical psychologists working with qualitative longitudinal data may draw on psychoanalytic theory to explain change or continuity in people's lives as determined in part by unconscious dynamics (see for example Hollway 2010; Lucey et al. 2003). In this context, data coding and analysis pay particular attention to affect, contradictions, deflections, exaggerations and reflections on early childhood relationships, all of which may point to psychodynamics. The same longitudinal data set could be worked with very differently by other researchers who do not subscribe to the notion of the unconscious or who do not believe in its operationalisation as an analytic lens in social science research. Many qualitative 
longitudinal researchers adopt narrative analysis as their conceptual lens, focusing on stories that are told as reflecting participants' conscious, subjective interpretation of their own experiences (see for example Shirani/Henwood 2011a; 2011b). In this case, data are not scoured for 'hidden' meanings underlying the participant's narrative, but it is the narrative structure and content that form the analytic focus. Ultimately what unites all forms of qualitative longitudinal data analysis is a concern with temporality, process and change.

\subsection{Ethics and limitations}

QLR is not without its challenges and limitations. Concerns include a perception that longitudinal research is necessarily expensive and risky, with potential problems maintaining research teams and participant engagement, together with the arduous nature of longitudinal data analysis (Thomson/Holland 2003). These challenges may give the impression that QLR is destined to be a marginal methodology that can only be deployed in small-scale research. However this is simply not the case as evidenced by the relatively recent Timescapes initiative, which involved five British universities and over 400 research participants through seven studies exploring various stages of the lifecourse (Neale et al. 2012). While Timescapes primarily conducted in-person interviews, technological advances are opening up new possibilities such as online interviews that may reduce travel costs (see Lean 2016a; 2016b). Social media also now provide easier routes for staying connected with participants in-between data collection phases, potentially reducing attrition, although this has brought its own ethical challenges in terms of reconnecting with participants (Miller 2015).

QLR often results in data sets on individual participants that amount to uniquely detailed data 'fingerprints' (Holland et al. 2006: 27). Presenting the findings of such research presents an ethical challenge in terms of achieving a sufficiently detailed analysis of individual cases while maintaining participant confidentiality. The revealing nature of longitudinal data also presents a challenge to obtaining informed consent because participants may not realise what researchers can 'see' of their lives, especially in extensive longitudinal studies in which long periods of time can elapse between data-collection periods (Thomson 2007). Allowing participants to access their own data provides transparency regarding the information that researchers have access to, which may help participants to decide whether or not they would like to continue to be involved in the research (ibid.). However, Hermanowicz (2013) warns that strategies such as this, together with the sustained contact that researchers have with participants, make it more likely that participants will discover the analytic claims of the research and potentially be unhappy with how they are represented.

Research relationships that extend over time can become highly complex and difficult to manage, which is especially the case in extensive research designs that span years. Embarking on a QLR journey requires 'ethical mindfulness' and careful maintenance of the relationship between researcher and participant (Warin 2011). Neale (2018: 83) argues that the foundation to sustaining ethical relationships in QLR is 'building trust, mutual respect and reciprocity in ways that do not lead to over-dependence or involvement, intrusion or neglect, to the detriment of either researcher or participant'. In so doing, she acknowledges that it can be challenging to balance the two ethical principles of reciprocity and professional boundaries. Reciprocity implies a two-way relationship in which the researcher and participant both benefit from the research. In the context of QLR, reciprocity may include financial 
reimbursement or gifts to acknowledge the significant time commitment that participation in the research may involve. However, gifting has the potential either to foster dependency or to blur the boundaries between personal and professional relationships in the research encounter (Derrington 2019; Neale 2018). Neale (2018: 77) suggests that QLR 'amplifies existing ethical considerations rather than raising new ones'. We can conclude that this amplification also relates to other challenges associated with the methodology, such as the potential for high costs and complex data analysis, which equally apply to other forms of qualitative research.

\section{TEMPORALITY AND BIOGRAPHY IN TOURISM RESEARCH}

Time has often been neglected in tourism research, forming an intangible and unacknowledged backdrop to the phenomena under investigation (Bærenholdt et al. 2004; Dickinson et al. 2013; Grabowski et al. 2016; Shirani/Henwood 2011a; Small 2016). This section presents a selective review of research on tourist temporality and biography, in order to illustrate the rich understanding that qualitative engagements with time can produce and to position QLR among competing methodologies. I begin by discussing lifecourse perspectives as a way of accessing temporal experience across various life stages before turning to biographical research, which analyses how we narrate the story of our lives. Existing QLR in tourism studies is then reviewed, providing empirical examples of the research designs and methods that were outlined in the previous section. This critical discussion identifies points of convergence and divergence between these three methodologies, and shows how lifecourse and biographical researchers have both critiqued and advocated QLR. I aim to resolve conceptual confusion that is present in the literature regarding use of the term 'longitudinal' and to address intersections between biography, narrative, temporality and longitudinality. I conclude by arguing that QLR provides a logical extension to existing qualitative research concerned with tourist temporality and biography.

\subsection{Lifecourse perspectives}

Lifecourse perspectives have long been called for in tourism studies as a way of understanding meanings and patterns of tourism at different stages of life (Gibson/ Yiannakis 2002; Gibson et al. 2012; Sedgley et al. 2011; Small 2008). Drawing on psychologist Daniel Levinson's work, Gibson/Yiannakis (2002: 362) suggest that the lifecourse can be divided into four overlapping eras that constitute its 'macrostructure': childhood and adolescence, early adulthood, middle adulthood and late adulthood. Within this macro-structure are ten developmental periods that constitute the 'micro-structure' of the lifecourse, including entry into early adulthood and the transition to middle age. In the tourism context, there is often overlap between research that is framed as a 'lifecourse' perspective and research labelled as 'biographical', given that both approaches largely rely on the analysis of biographical narratives (cf. Gibson et al. 2012; Gram et al. 2019; Huber 2019; Huber et al. 2017; Sedgley 2007; Sedgley et al. 2011). The distinction between the two lies in the analytic weight given to the concept of life stages, which is more prominent in lifecourse research. Biographical research, on the other hand, does not necessarily reference life stages and may adopt a less temporally segmented approach to the analysis of narratives and the passage of time. 
Gibson et al.'s (2012) qualitative study of 'girlfriend getaways' - a term denoting women taking vacations together - shows the insight that a lifecourse approach can provide in tourism research. They conducted interviews and focus groups with women ranging in age from their early twenties to late eighties. Gibson et al. report that although certain aspects of girlfriend getaways appear to remain constant throughout the lifecourse, such as feelings of freedom and the role of friendship, the travel experience takes on new meanings at different life stages. In adolescence, girlfriend getaways were framed as an act of rebellion against parents and as a way of cementing childhood friendships. The researchers observed a significant shift in the meanings associated with these trips during early adulthood. Many of the women started travelling with their mothers during this life stage, allowing the women to relate to one another in a new way as travel companions and friends, which often signified a positive shift in their relationship. During early adulthood, many women also commented on their temporal experience as the busyness of life increased, resulting in a lack of time to travel with friends. In middle adulthood, girlfriend getaways were characterised by escapism and a chance to feel young again. Whereas in late adulthood, the women again discussed a lack of time, not in relation to busy schedules preventing them from travelling, but to the growing awareness of their mortality and a sense of time running out. This study thus intricately weaves together a qualitative analysis of subjective temporal experience with a lifecourse perspective that foregrounds meanings at each stage of life. However, the research is dependent on retrospective narratives generated at one point in time, which limits its explanatory power in terms of the real time experience of life transitions in relation to travel.

Gram et al.'s (2019) interview-based research on 'grandtravel' connects temporal experience through travel to affective flows, inter-generational dynamics and the lifecourse. Grandtravel can be defined as 'family holidays including grandparents, sometimes without parents present' (ibid.: 2). The authors show how time can become relationally contested as family members express different temporal needs, leading potentially to conflicts between the need for 'together time' and 'own time'. Gram et al. (ibid.: 2) conceptualise family members as embedded in 'complex collective timescapes' that involve intersections between biographical, generational and historical time in addition to the more widely recognised configuration of clock time. Presenting a departure from lay understandings of holidays as 'time out', they suggest that grandtravel represents 'an intensification rather than an abrupt departure from everyday together time' (ibid.: 9). A focus on the lifecourse sensitises this research to the embodied dimension of travel; while grandchildren are on a future trajectory of physical and cognitive growth, grandparents face the inevitability of physical and cognitive decline. This inter-generational intersection, in which opposite ends of the lifecourse meet, produces interesting temporal possibilities in which time is enjoyed in the moment while carrying resonances of loss associated with the finitude of the individual human life. Gram et al. (2019) conclude by advocating QLR as a way of advancing future research into the phenomenon of grandtravel. In particular, I argue that QLR could shed light on how intersecting trajectories of growth and decline play out over time, as well as providing methods for charting the transition into grandparenthood and grandtravel.

\subsection{Biographical research}

Biographical research focuses on how we narrate the story of our lives. It has proved popular in the study of senior tourists (Huber et al. 2017; Sedgley 2007; Sedgley et al. 
2011), although there is no reason why the approach could not be used to examine the experiences of younger participants. Sedgley et al. (2011: 430) observe that there has been limited uptake of this methodology in tourism research, even though it can provide 'a life course perspective that opens up complex, personalized and finegrained understandings of a person's motivation for participating in tourism'. Written almost ten years ago, this assessment of the field is as relevant today as it was then. Reflecting one of the primary aims of longitudinal approaches, biographical research sets out to situate the individual life, or life story, within a broader context of social, economic and historical change. Huber et al. (2017) suggest that the temporal distance from past life events afforded by the biographical interview allows key turning points to be retrospectively identified. Indeed, time comes into play in multiple ways in biographical research, from a temporal perspective on life events, to changing temporal experiences during different stages of the lifecourse, to an analysis of how the passing of time brings change or continuity. The approach has been identified as potentially illuminating on the formation of tourist identity, motivation, loyalty and experience.

Elsrud's (1998) study of Swedish women backpackers presents a compelling articulation of tourist biography, narrative and temporality. She relates the minutiae of everyday subjective temporal experience during travel - such as changes from the regulation of clock time to synchronisation with more natural bodily rhythms - to how travel features more broadly within biographical narratives. In doing this, she draws on Alheit's (1994: 305) distinction between "“everyday time" as something relatively routine, or cyclical, and "life time" as a linearly experienced framework in which we seek biographical continuity and coherence'. Elsrud demonstrates how these two temporalities operate in tourism, as new temporal experiences such as the escape from routines on holiday can provoke a questioning of everyday time that provides the basis of reflexive adaptations of the tourist's biography. Elsrud uses the example of the beach to illustrate this, arguing that it is a site where a multiplicity of time dimensions can be found as travellers structure and order their experiences through private reflection, diary-keeping and letters to friends and family; to which we could add contemporary social media practices. The beach affords periods of 'rest' for backpackers, enacting a change of pace and temporality, and can serve 'as a place for putting together experiences into a biographical whole' (Elsrud 1998: 325). While Elsrud's study presents a theoretically rich account of biography in relation to travel, its reliance on the single interview method means that this richness is not always reflected empirically. It provides rather static snapshots of the women's travel experiences rather than the more dynamic account of biographical narrative construction that is possible in QLR.

The advancement of biographical research in tourism studies has been hindered by terminological and conceptual confusion. One problem regards how memory is conceptualised in relation to biographical narratives. Huber et al. (2017: 28) suggest that 'recall error' may limit research reliability, Ladkin (2004: 242) complains of the 'fallibility of human memory', and Sedgley (2007) questions the accuracy of life stories as told in biographical interviews. There is a need for researchers to clarify the extent to which biographical narratives are being mined for accurate representations of past travel events or whether the purpose of exploring such narratives is to reveal subjective experience in the present. If it is the latter, then memory and narrative serve to 'build up a picture of the past from the perspective of the present, and the present is understood through the lens of past experiences' (Neale/Flowerdew 2003: 193). A second issue relates to use of the term 'longitudinal' in biographical research. Ladkin 
(2004: 239) states that biographical and life history methods 'collect information over time', apparently implying a longitudinal research design. However it is clear that this is not what Ladkin means given her dismissal of longitudinal data collection, which I will come to shortly. Huber et al. (2017: 28) state that biographical research can be categorised as 'retrospective longitudinal research', by which they mean that one data-collection phase is used to 'retrieve temporal data from the past'. Although these authors are not alone in referring to methods that use retrospection as 'longitudinal', the term is unhelpful in this context given that, surely, all qualitative interviews involve a degree of retrospection; whether or not it is the entire life story that is being shared, interviews nearly always involve memory and the narration of past experiences.

Ladkin's (2004) advocacy of the retrospective life history method, which is practically synonymous with biographical research, rests partly on a dismissal of longitudinal data generation. She admits that longitudinal research in tourism is 'unique' in its explanatory power regarding causality and processes of change, framing retrospective life story approaches as a necessary next-best option. Ladkin lists two main factors that inhibit the use of longitudinal methods in tourism research: the first is attrition, whereby some participants are likely to disengage from the research over time; the second is high cost, due to making repeat visits to individuals or communities. Her rather startling conclusion is that 'these factors rule out the use of longitudinal surveys in tourism research, as in any other branch of social science research' (ibid.: 241, emphasis added). These comments now read as somewhat dated but I suspect that many tourism researchers continue to share Ladkin's concerns. As I have shown in my review of recent methodological literature, QLR is very much alive in the social sciences. Furthermore, new digital technologies have expanded the possibilities of QLR, making it easier to keep in contact with participants (potentially reducing attrition) and enabling data collection to take place virtually (reducing research costs). In the following section, I discuss the increasing use of QLR in tourism studies.

\subsection{Qualitative longitudinal research}

In the last five years, a number of studies using QLR have emerged in the tourism literature. While longitudinal ethnography is an established methodology in tourism research (Cole 2004; Graburn 2002; Sterchele 2020; Tucker 2005; 2010), these latest studies represent increasing methodological plurality under the QLR umbrella. Examples of new approaches include Frochot et al.'s (2019) intensive study of ski tourists, whom they interviewed on each day of a one-week resort stay in order to document in sequential detail the holiday appropriation process. At the other end of the durational spectrum is Lean's (2016a; 2016b) ten-year study of transformative travel, which used online message boards and repeated email interviews with tourists from all over the world. The sub-fields of transformative travel and volunteer tourism have taken a particular interest in longitudinal methodologies, which is no surprise given their investment in explaining psychological or behavioural changes in tourists and processes of reintegration following periods of travel. In this section, I critically discuss three studies that use QLR within these sub-fields, drawing out their contributions to our broader comprehension of tourist temporality and narrative.

Lean (2016a) argues that travel occurs in three temporal phases: 'before', 'during' and 'after'. These chronological distinctions form part of narrative conventions that people use to interpret the passage of time and thus provide relatable analytic frames 
of reference. Of these three temporal phases, it is the 'during' and the immediate 'after' that we know most about given that this is when data generation is most likely to occur within tourism research. Lean highlights the importance of also attending to the inspiration, motivation, anticipation, preparation and expectation that constitute what happens 'before' tourists embark on physical travel. Equally important is the 'after' phase, which he conceptualises as an indefinite period following a traveller's return that involves iterations of remembering and meaning-making, and reconfigurations of social relationships that can result in psychological or behavioural transformation. It is the richness of experience during these two temporal phases bookending tourism that we miss out on with conventional methodologies. This results in a 'limited temporal scope' that develops 'a static perspective of both travel and transformation' (Lean 2016a: 204). This theorisation is extended in the work of Ingram et al. (2017), who divide tourist experience into 'prospective' (pre-holiday), 'active' (on holiday) and 'reflective' (post-holiday) phases through their PARTicipative inquiry methodology.

Temporally broadening the analytic focus of tourism research and re-evaluating the ontological separation between touristic and non-touristic experience have long been called for. Small (1999: 34), for example, argues that 'tourism cannot be disconnected from the broader social and temporal context. The construction of the tourist experience is related to the construction of everyday life experiences'. Similarly, Hall (2005: 96-97) invites qualitative research to engage with 'individual and collective mobility biographies over the life-course' and warns that without such a holistic approach 'we are forever doomed to see tourism's effects only at the destination scale rather than as part of a broader understanding of mobility'. The increasing convergence of tourism and contemporary lifestyle mobilities further underscores the 'need for longitudinal research that tracks how changes evolve over time and are influenced by ongoing mobilities' (Lean 2016a: 24). These arguments for greater spatio-temporal contextualisation of tourist experience provide a strong justification for exploring the potential of QLR. I will now discuss two pertinent studies of volunteer tourism in order to illustrate how a longitudinal methodology can enhance analyses of narrative, transformation and post-trip reintegration.

Grabowski et al.'s (2016) study of time as a cultural construct involved repeated interviews with volunteer tourists travelling to Costa Rica, Mexico and Vanuatu. These were conducted two weeks prior to departure, immediately upon return and then six months later, with a total data generation period of approximately nine months. They analyse volunteer tourists' experiences of non-Western time as a form of cultural alterity involving a slower pace of life and reduced punctuality. Respondents described stressful readjustments to the temporal norms of their home society, detailing regimented routines, the experience of 'time scarcity' and feeling as if time had 'stood still' while they had been travelling. Grabowski et al. (2016: 8) summarise that 'volunteer tourists' experience of home, before departure and on return, includes a faster pace of living on a linear time scale. Time to the volunteer tourist is "plentiful" and social while they are in-country, yet commoditized, scarce and routinized upon re-entry'. The effects of reintegration into one's home society are particularly important in the context of volunteer tourism, which has been promoted as a form of transformative travel. Grabowski et al. note that it is only upon re-entry that volunteer tourists start understanding the personal impact of their travel, so temporal experiences that prompt such reflection are likely to be significant. While these findings are original, the authors provide limited reflection on the longitudinality of their data set and data extracts from the pre-departure interviews are not featured. 
My own research on the role of emotions in volunteer tourists' moral transformations (É. Crossley 2012a; 2012b) shares an almost identical repeat-interview design with the addition of interviews during the volunteering and a longer data-generation period of eleven months. The study's diachronic analysis makes explicit the utility of generating data longitudinally by providing a view of how sense-making changes over time before cohering into the eventual retrospective narrative of the transformative experience. In one write-up of the research (É. Crossley 2012b), I trace the accounts of three volunteer tourists through time in order to reveal how narratives of moral transformation through travel are constructed. In one pre-travel narrative, a participant describes how she expects to be 'heartbroken' by the sight of poverty in Kenya, where she will soon volunteer. However, the volunteer tourist puts a positive spin on this by saying that the experience will enable her to realise how 'lucky' she is to live in a wealthy country and that she will 'be a better person for it'. I identify this as a discourse of 'redemptive poverty' in which travel to poor countries is used by tourists to develop 'appreciation', 'perspective' or 'gratitude'. We subsequently learn from an interview conducted in Kenya that the volunteer tourist did not experience the anticipated emotion and that, as a result, sadness as a gateway to moral betterment disappeared completely from her post-travel narrative. Through conducting pre-travel interviews, this expectation of emotional distress when confronted by poverty was revealed within the research in a way that it might not have been through purely retrospective narrative methods.

Thomson/Holland (2003: 242) highlight the potentially problematic nature of repeat interviews, suggesting that they can have normative effects such as producing 'narratives of progress and development'. This issue is especially relevant for research that focuses on narratives of transformative travel. However we know from Noy's (2004) work on youth backpacker travel that even in the absence of a repeat-interview research design, certain types of tourism carry a rhetorical inevitability of generating narratives on pivotal moments and personal change. It is therefore worth questioning whether it is, as Thomson and Holland suspect, the repeat-interview method that generates narratives of progress and development or whether this biographical narrative structure is more deeply embedded in the sense we make of the passing of time and the significance that we assign to travel. As evidenced by my research (É. Crossley 2012b), narratives of anticipated personal transformation that emerge before travel do not necessarily make it into the 'final cut' retrospective narrative if a tourist's expectations are not met or there is a pivot in their personal goals. I argue that in a tourism context narratives of progress and change are likely to be produced regardless of whether a single- or repeat-interview method is used. The advantage conferred by the use of QLR is that we gain insight into tourist experience at each temporal stage of travel, as well as the emergence, curation and disappearance of biographical narratives over time.

\section{CONCLUSION}

Longitudinality can only be understood in relation to time and yet, as I have shown in this paper, the two concepts are not equivalent. As Henwood/Shirani (2012: 209) note, time provides both a 'topic of study' and a 'vehicle of study'. The former is exemplified in the context of tourism studies by a multitude of approaches showing how time structures and mediates tourism practice, discourse and experience. Qualitative research on the subjective experience of time through tourism has developed our 
comprehension of how temporal qualities such as pace, rhythm and routine affect tourists. As a vehicle of study, time has been under-utilised in tourism studies; we suffer from an over-reliance on data collected at one point in time and the retrospective framing of experiences. When QLR is undertaken, a choice must be made regarding the extent to which time will also be treated as a topic of study. The version of QLR that I have expounded is one that does concern itself with temporality but this is not an inherent feature of the approach and it is possible to trace change and process through time qualitatively without an explicit focus on subjective temporal experience. Such are the complexities of research on/through time and hence why I have provided conceptual clarification regarding the use of terms such as 'longitudinal' and 'temporal'.

I want to finish by reflecting further on the distinction between 'intensive' and 'extensive' longitudinal research designs, and their potential application in tourism studies. Intensive longitudinal research is conducted over a shorter time-frame but involves frequent waves of data collection whereas extensive research elapses over a longer time-frame with more infrequent waves of data collection. An intensive design can be found in the work of Grabowski et al. (2016) and my own (É. Crossley 2012a; $2012 b$ ), in which data generation spanned several months and was temporally structured around a single travel experience in order to capture narratives of the (immediate) 'before', 'during' and 'after'. This design allows researchers to follow tourists in real time as they choose, anticipate, undertake and recollect their travels. Such studies provide a detailed perspective on social reintegration following periods of travel that can shed new light on processes of psychological and behavioural transformation. They also allow us to trace the emergence and iterative construction of travel, or biographical, narratives. The intensive approach to QLR may be more straightforward to undertake in tourism studies compared to its extensive counterpart; attrition, for example, is less of an issue when conducting research over weeks or months rather than years, and research can be completed within time-frames that are more compatible with funding requirements.

Extensive longitudinal research designs come with no alleviation of the challenges typically attributed to QLR but Lean's (2016a; 2016b) decade-long study of transformative travel shows that it can be done. While intensive design provides a temporally detailed perspective on a particular period of travel, the extensive approach can enhance our understanding of the broader patterns, meanings and long-term impacts of tourism within a person's life. Extensive longitudinal research therefore has greater potential to enhance biographical and lifecourse approaches. For example, a study may span the years between adolescence and early adulthood, building knowledge on how travel is negotiated in relation to key transitions that constitute the 'micro-structure' of the lifecourse (Gibson/Yiannakis 2002). As with the intensive approach, extensive QLR allows us to witness the emergence of biographical narratives, although the slower research tempo will provide a less 'fine-grained' view of this process (Sedgley et al. 2011). Instead, it connects stories of travel to biographical narratives, broadening our analytic focus to encompass the non-touristic aspects of everyday life, thereby reconnecting tourists to their 'broader social and temporal context' (Small 1999: 34).

In conclusion, I have argued that QLR can significantly enhance our understanding of tourist experience, subjectivity, motivation and transformation. Returning to M.L. Crossley's (2000: 534) observation that '[o]ur experience automatically assumes temporally extended forms in which future, present and past mutually determine one another as parts of a whole', it would seem that part of the task of qualitative research 
is to investigate this temporal extension and experience. In doing so, QLR not only enriches our understanding of tourist subjectivity in a temporal sense but also contextually by reconnecting knowledge about tourism to tourists' everyday lives. The second broad advantage of QLR is its ability to capture people's personal experience of changing circumstances. Writing at a time when the world is still gripped by the COVID-19 pandemic of 2020, tourism scholars may find that longitudinal methodologies have new appeal. Opportunities may arise to trace consumers' changing perceptions of travel within a newly restrictive climate, while longitudinal studies of those employed by the tourism industry may yield new insight into resilience and regeneration during a time of global crisis and beyond. At this historic moment, we have an opportunity to walk alongside and learn from individuals as they negotiate the changing landscape of tourism.

\section{REFERENCES}

Abbott, A. (2001): Time Matters: On Theory and Method, Chicago: University of Chicago Press. Adam, B. (1990): Time and Social Theory, Cambridge, UK: Polity Press.

Adam, B. (1995): Timewatch: The Social Analysis of Time, Cambridge, UK: Polity Press.

Alheit, P. (1994): Everyday time and life time: on the problems of healing contradictory experiences of time, in: Time and Society, 3(3), 305-319.

Bærenholdt, J.O., Haldrup, M., Larsen, J., Urry, J. (2004): Performing Tourist Places, London: Ashgate.

Bagnoli, A. (2009): Beyond the standard interview: the use of graphic elicitation and arts-based methods, in: Qualitative Research, 9(5), 547-570.

Cohen, E. (1986): Tourism and time, in: World Leisure and Recreation, 28(5), 13-16.

Cole, S. (2004): Shared benefits: longitudinal research in eastern Indonesia, in: Phillmore, J., Goodson, L. (eds), Qualitative Research in Tourism: Ontologies, Epistemologies and Methodologies, London: Routledge, 292-310.

Corden, A., Millar, J. (2007): Time and change: a review of the qualitative longitudinal research literature for social policy, in: Social Policy and Society, 6, 583-592.

Crossley, É. (2012a): Poor but happy: volunteer tourists' encounters with poverty, in: Tourism Geographies, 14(2), 235-253.

Crossley, É. (2012b): Affect and moral transformations in young volunteer tourists, in: Picard, D., Robinson, M. (eds), Emotion in Motion: Tourism, Affect and Transformation, London: Ashgate, 85-98.

Crossley, M.L. (2000): Narrative psychology, trauma and the study of self/identity, in: Theory and Psychology, 10(4), 527-546.

Derrington, M.L. (2019): Qualitative Longitudinal Methods, London: SAGE Publishing.

Desforges, L. (2000): Traveling the world: identity and travel biography, in: Annals of Tourism Research, 27(4), 926-945.

Dickinson, J.E., Lumsdon, L. (2010): Slow Travel and Tourism, London: Routledge.

Dickinson, J.E., Peeters, P. (2014): Time, tourism consumption and sustainable development, in: International Journal of Tourism Research, 16(1), 11-21.

Dickinson, J.E., Lumsdon, L.M., Robbins, D. (2011): Slow travel: issues for tourism and climate change, in: Journal of Sustainable Tourism, 19(3), 281-300.

Dickinson, J.E., Filimonau, V., Cherrett, T., Davies, N., Norgate, S., Speed, C., Winstanley, C. (2013): Understanding temporal rhythms and travel behaviour at destinations: potential ways to achieve more sustainable travel, in: Journal of Sustainable Tourism, 21(7), 1070-1090.

Edensor, T. (2012): The rhythms of tourism, in: Minca, C., Oakes, T. (eds), Real Tourism: Practice, Care, and Politics in Contemporary Travel Culture, London: Routledge, 68-85. 
Elliott, J., Holland, J., Thomson, R. (2008): Longitudinal and panel studies, in: Alasuutari, P., Bickman, L., Brannen, J. (eds), The SAGE Handbook of Social Research Methods, London: SAGE Publishing, 228-248.

Elsrud, T. (1998): Time creation in travelling: the taking and making of time among women backpackers, in: Time and Society, 7(2-3), 309-334.

Fennell, D.A. (1996): A tourist space-time budget in the Shetland Islands, in: Annals of Tourism Research, 23(4), 811-829.

Flaherty, M.G. (2003): Time work: customizing temporal experience, in: Social Psychology Quarterly, 66(1), 17-33.

Flaherty, M.G. (2011): The Textures of Time: Agency and Temporal Experience, Philadelphia: Temple University Press.

Frochot, I., Kreziak, D., Statia, E. (2019): Home away from home: a longitudinal study of the holiday appropriation process, in: Tourism Management, 71, 327-336.

Fullagar, S., Markwell, K., Wilson, E. (eds) (2012): Slow Tourism: Experiences and Mobilities, Bristol: Channel View Publications.

Germann Molz, J. (2009): Representing pace in tourism mobilities: staycations, slow travel and the amazing race, in: Journal of Tourism and Cultural Change, 7(4), 270-286.

Germann Molz, J. (2010): Performing global geographies: time, space, place and pace in narratives of round-the-world travel, in: Tourism Geographies, 12(3), 329-348.

Gibson, H., Yiannakis, A. (2002): Tourist roles: needs and the lifecourse, in: Annals of Tourism Research, 29(2), 358-383.

Gibson, H.J., Berdychevsky, L., Bell, H.L. (2012): Girlfriend getaways over the life course: change and continuity, in: Annals of Leisure Research, 15(1), 38-54.

Grabowski, S., Wearing, S.L., Small, J. (2016): Time as culture: exploring its influence in volunteer tourism, in: Tourism Recreation Research, 41(1), 26-36.

Graburn, N. (2002): The ethnographic tourist, in: Dann, G.M.S. (ed.), The Tourist as a Metaphor of the Social World, New York: CABI Publishing, 19-39.

Gram, M., O’Donohoe, S., Schänzel, H., Marchant, C., Kastarinen, A. (2019): Fun time, finite time: temporal and emotional dimensions of grandtravel experiences, in: Annals of Tourism Research, 79, No 102769.

Hall, C.M. (2005): Time, space, tourism and social physics, in: Tourism Recreation Research, 30(1), 93-98.

Hassard, J. (1990): Introduction: the sociological study of time, in: Hassard, J. (ed.), The Sociology of Time, New York: Palgrave Macmillan, 1-18.

Henderson, S., Holland, J., McGrellis, S., Sharpe, S., Thomson, R. (2012): Storying qualitative longitudinal research: sequence, voice and motif, in: Qualitative Research, 12(1), 16-34.

Henwood, K., Finn, M. (2010): Researching masculine and paternal subjects in times of change: insights from a QLL and psychosocial case study, in: Thomson, R. (ed.), Intensity and Insight: Qualitative Longitudinal Methods as a Route to the Psycho-Social, Timescapes Working Paper Series 3, Leeds, UK: University of Leeds, 34-45, URL: http://www.timescapes. leeds.ac.uk/ assets/files/WP3-final-Jan-2010.pdf (accessed 20 September 2019).

Henwood, K., Shirani, F. (2012): Researching the temporal, in: Cooper, H.M., Camic, P.M., Long, D.L., Panter, A.T., Rindskopf, D.M., Sher, K.J. (eds), Handbook of Research Methods in Psychology, Volume 2: Research Designs: Quantitative, Qualitative, Neuropsychological, and Biological, Washington, DC: APA Publications, 209-223.

Hermanowicz, J.C. (2013): The longitudinal qualitative interview, in: Qualitative Sociology, 36(2), 189-208.

Holland, J., Thomson, R. (2009): Gaining perspective on choice and fate, in: European Societies, 11(3), 451-469.

Holland, J., Thomson, R., Henderson, S. (2006): Qualitative longitudinal research: a discussion paper, Families \& Social Capital ESRC Research Group Working Paper No 21, London: London South Bank University, URL: https://www.lsbu.ac.uk/_data/assets/ pdf_file/0019/ 9370/qualitative-longitudinal-research-families-working-paper.pdf.

Hollway, W. (2010): Preserving vital signs: the use of psychoanalytically informed interviewing and observation in psycho-social longitudinal research, in: Thomson, R. (ed.), Intensity and 
Insight: Qualitative Longitudinal Methods as a Route to the Psycho-Social, Timescapes Working Paper Series 3, Leeds, UK: University of Leeds, URL: http://www.timescapes. leeds.ac.uk/ assets/files/WP3-final-Jan-2010.pdf (accessed 20 September 2019).

Holstein, J.A., Gubrium, J.F. (2007): Constructionist perspectives on the life course, in: Sociology Compass, 1(1), 335-352.

Huber, D. (2019): A life course perspective to understanding senior tourism patterns and preferences, in: International Journal of Tourism Research, 21(3), 372-387.

Huber, D., Milne, S., Hyde, K.F. (2017): Biographical research methods and their use in the study of senior tourism, in: International Journal of Tourism Research, 19(1), 27-37.

Ingram, C., Caruana, R., McCabe, S. (2017): PARTicipative inquiry for tourist experience, in: Annals of Tourism Research, 65, 13-24.

Jones, J.M., Brown, W.T. (2005): Any time is Trinidad time! Cultural variations in the value and function of time, in: Strathman, A., Joireman, J. (eds), Understanding Behavior in the Context of Time: Theory, Research, and Application, Mahwah, NJ: Lawrence Erlbaum Associates, 305-323.

Krakover, S. (2002): Time dimension and tourism development in peripheral areas, in: Krakover, S., Graduse, Y. (eds), Tourism in Frontier Areas, Lanham, MD: Lexington Books, 21-37.

Ladkin, A. (1999): Life and work history analysis: the value of this research method for hospitality and tourism, in: Tourism Management, 20(1), 37-45.

Ladkin, A. (2004): The life and work history methodology: a discussion of its potential use for tourism and hospitality research, in: Phillmore, J., Goodson, L. (eds), Qualitative Research in Tourism: Ontologies, Epistemologies and Methodologies, London: Routledge, 236-254.

Lean, G. (2016a): Transformative Travel in a Mobile World, Wallingford, UK: CABI Publishing.

Lean, G. (2016b): Investigating perpetual travel: email interviews and longitudinal methods in travel, tourism and mobilities research, in: Duncan, T., Cohen, S.A., Thulemark, M. (eds), Lifestyle Mobilities: Intersections of Travel, Leisure and Migration, Abingdon, UK: Routledge, 99-112.

Lucey, H., Melody, J., Walkerdine, V. (2003): Project 4: 21 transitions to womanhood developing a psychosocial perspective in one longitudinal study, in: International Journal of Social Research Methodology, 6(3), 279-284.

Lumsdon, L.M., McGrath, P. (2010): Developing a conceptual framework for slow travel: a grounded theory approach, in: Journal of Sustainable Tourism, 19(3), 265-279.

May, J., Thrift, N. (2003): Introduction, in: May, J., Thrift, N. (eds), Timespace: Geographies of Temporality, London: Routledge, 1-46.

McCabe, S. (2002): The tourist experience and everyday life, in: Dann, G.M.S. (ed.), The Tourist as a Metaphor of the Social World, Wallingford, UK: CABI Publishing, 61-76.

McLeod, J., Thomson, R. (2009): Researching Social Change: Qualitative Approaches, London: SAGE Publishing.

Miller, T. (2015): Going back: 'stalking', talking and researcher responsibilities in qualitative longitudinal research, in: International Journal of Social Research Methodology, 18(3), 293-305.

Neale, B. (2015): Time and the lifecourse: perspectives from qualitative longitudinal research, in: Worth, N., Hardill, I. (eds), Researching the Lifecourse: Critical Reflections from the Social Sciences, Bristol: Policy Press, 25-41.

Neale, B. (2018): What is Qualitative Longitudinal Research?, London: Bloomsbury Academic.

Neale, B., Flowerdew, J. (2003): Time, texture and childhood: the contours of longitudinal qualitative research, in: International Journal of Social Research Methodology, Theory and Practice, 6(3), 189-199.

Neale, B., Henwood, K., Holland, J. (2012): Researching lives through time: an introduction to the Timescapes approach, in: Qualitative Research, 12(1), 4-15.

Norum, R., Mostafanezhad, M. (2016): A chronopolitics of tourism, in: Geoforum, 77, 157-160.

Noy, C. (2004): This trip really changed me: backpackers' narratives of self-change, in: Annals of Tourism Research, 31(1), 78-102.

Pearce, D.G. (1988): Tourist time-budget, in: Annals of Tourism Research, 15(1), 106-121. 
Ryan, C. (2002): 'The time of our lives' or time for our lives: an examination of time in holidaying, in: Ryan, C. (ed.), The Tourist Experience, London: Continuum, 201-212.

Saldaña, J. (2003): Longitudinal Qualitative Research: Analyzing Change Through Time, Walnut Creek, CA: Altamira Press.

Sedgley, D. (2007): The contribution of biographical research in understanding older women's leisure, in: Ateljevic, I., Pritchard, A., Morgan, N. (eds), The Critical Turn in Tourism Studies: Innovative Research Methodologies, Oxford: Elsevier, 331-348.

Sedgley, D., Pritchard, A., Morgan, N. (2011): Tourism and ageing: a transformative research agenda, in: Annals of Tourism Research, 38(2), 422-436.

Shirani, F., Henwood, K. (2011a): Taking one day at a time: temporal experiences in the context of unexpected life course transitions, in: Time and Society, 20(1), 49-68.

Shirani, F., Henwood, K. (2011b): Continuity and change in a qualitative longitudinal study of fatherhood: relevance without responsibility, in: International Journal of Social Research Methodology, 14(1), 17-29.

Small, J. (1999): Memory-work: a method for researching women's tourist experiences, in: Tourism Management, 20(1), 25-35.

Small, J. (2008): The absence of childhood in tourism studies, in: Annals of Tourism Research, 35(3), 772-789.

Small, J. (2016): The experience of time in long-term travel, in: Tourism Geographies, 18(4), 341-358.

Stein, K. (2012): Time off: the social experience of time on vacation, in: Qualitative Sociology, $35(3), 335-353$.

Sterchele, D. (2020): Memorable tourism experiences and their consequences: an interaction ritual (IR) theory approach, in: Annals of Tourism Research, 81, No 102847.

Tamboukou, M. (2008): Re-imagining the narratable subject, in: Qualitative Research, 8(3), 283-292.

Thomson, R. (2007): The qualitative longitudinal case history: practical, methodological and ethical reflections, in: Social Policy and Society, 6(4), 571-582.

Thomson, R., Holland, J. (2003): Hindsight, foresight and insight: the challenges of longitudinal qualitative research, in: International Journal of Social Research Methodology, 6(3), 233244.

Thomson, R., McLeod, J. (2015): New frontiers in qualitative longitudinal research: an agenda for research, in: International Journal of Social Research Methodology, 18(3), 243-250.

Trapp-Fallon, J. (2003): Searching for rich narratives of tourism and leisure experience: how oral history could provide an answer, in: Tourism and Hospitality Research, 4(4), 297-306.

Trapp-Fallon, J. (2007): Pursuing the past: using oral history to bring transparency to the research process, in: Ateljevic, I., Pritchard, A., Morgan, N. (eds), The Critical Turn in Tourism Studies: Innovative Research Methodologies, Oxford: Elsevier, 317-330.

Tucker, H. (2005): Living with Tourism: Negotiating Identities in a Turkish Village, London: Routledge.

Tucker, H. (2010): Peasant-entrepreneurs: a longitudinal ethnography, in: Annals of Tourism Research, 37(4), 927-946.

Varley, P., Semple, T. (2015): Nordic slow adventure: explorations in time and nature, in: Scandinavian Journal of Hospitality and Tourism, 15(1-2), 73-90.

Warin, J. (2011): Ethical mindfulness and reflexivity: managing a research relationship with children and young people in a 14-year qualitative longitudinal research (QLR) study, in: Qualitative Inquiry, 17(9), 805-814.

White, N.R., White, P.B. (2007): Home and away: tourists in a connected world, in: Annals of Tourism Research, 34(1), 88-104.

Wood, D. (2001): The Deconstruction of Time, Evanston, IL: Northwestern University Press.

Yates, L. (2003): Interpretive claims and methodological warrant in small-number qualitative, longitudinal research, in: International Journal of Social Research Methodology, 6(3), 223-232. 
Temporality and biography in tourism: a qualitative longitudinal approach 111

Zeruvabel, E. (1981): Hidden Rhythms: Schedules and Calendars in Social Life, Chicago: University of Chicago Press.

Zerubavel, E. (1982): The standardization of time: a sociohistorical perspective, in: American Journal of Sociology, 88(1), 1-23. 